\title{
Optimization of Culture Conditions for Amoxicillin Degrading Bacteria Screened from Pig Manure
}

\author{
Xuanjiang Yang ${ }^{1,2}$, Panpan Guo ${ }^{1}$, Miao Li ${ }^{1, *}$, Hualong $\mathrm{Li}^{1}$, Zelin $\mathrm{Hu}^{1}{ }^{1}$, Xianwang Liu ${ }^{1}$ and \\ Qiang Zhang ${ }^{3}$ \\ 1 Institute of Intelligent Machinery, Hefei Institute of Material Sciences, Chinese Academy of Sciences, \\ Hefei 230031, China; xjyang@mail.ustc.edu.cn (X.Y.); panpan2019520@163.com (P.G.); hlli@iim.ac.cn (H.L.); \\ zlhu@iim.ac.cn (Z.H.); lxw440@163.com (X.L.) \\ 2 Hefei Institutes of Physical Science, Chinese Academy of Sciences, University of Science and Technology \\ of China, Hefei 230026, China \\ 3 Department of Biosystems Engineering, University of Manitoba, Winnipeg, MB R3T 5V6, Canada; \\ Qiang.Zhang@umanitoba.ca \\ * Correspondence: mli@iim.ac.cn; Tel.: +86-189-6181-2279
}

Received: 30 November 2019; Accepted: 10 February 2020; Published: 17 March 2020

\begin{abstract}
Objective: The objective of this study was to screen amoxicillin (AMX)-degrading bacterial strains in pig manure and optimize the fermentation conditions for these strains to achieve high fermentation rate, which can provide an effective way for the practical application of bacterial strains as antibiotic-degrading bacterial in treating livestock waste for antibiotic residues. (2) Methods: Antibiotic susceptibility tests and high-performance liquid chromatography tandem mass spectrometry (HPLC-MS/MS) were employed to screen AMX-degrading bacterial strains in pig manure. The culture conditions were optimized for AMX-degrading bacterial strains using Plackeet-Burman design (PBD), the steepest ascent design, and the response surface methods, coupled with the Box-Behnken design (BBD). The effects of culture time, temperature, rotator (mixing) speed, inoculum level, and initial $\mathrm{pH}$ value on the growth of AMX-degrading strains were investigated. Experimental data obtained from BBD were utilized to generate a second-order polynomial regression model for evaluating the effects of the tested variables on the optical density at $600 \mathrm{~nm}\left(\mathrm{OD}_{600}\right)$ of culture solutions as the growth indicator for the screened AMX-degrading strains. (3) Results: The initial $\mathrm{pH}$, culture time, and the inoculum level had significant effects on the $\mathrm{OD}_{600}$ value (growth) of the screened AMX-degrading strains. The initial $\mathrm{pH}$ value was found to be the most critical factor influencing the growth of bacteria. The optimized culture condition for the bacterial growth determined by the response surface methodology was: the initial $\mathrm{pH}$ of 6.9 , culture time of $52 \mathrm{~h}$, and inoculum level of $2 \%$. The average OD value of 12 different fermentation conditions in the initial fermentation tests in this study was 1.72 and the optimization resulted in an OD value of 3.00. The verification experiment resulted in an OD value of 2.94, which confirmed the adequacy of the optimization model for the determining the optimal culture condition. (4) Conclusions: The growth of the screened strain of AMX-degrading bacteria could be optimized by changing the fermentation conditions. The optimization could be achieved by using the Box-Behnken response surface method and Plackett-Burman experimental design.
\end{abstract}

Keywords: amoxicillin; biodegradation; Plackett-Burman; Box-Behnken design; culture condition

\section{Introduction}

Amoxicillin (AMX) is a broad-spectrum therapeutic antibiotic that can penetrate the cell walls of bacteria and thus kill pathogenic $\mathrm{G}^{+}$and $\mathrm{G}^{-}$bacteria (including coccus and bacillus) [1]. AMX has 
been commonly used in intensive livestock production because it is considered to be effective in treating a variety of animal diseases. However, like most antibiotics, AMX cannot be completely decomposed in the animal body and residues are excreted in the form of protoplasts or metabolic intermediates, which may eventually enter the environment [2]. AMX residues discharged into the soil and groundwater environment are harmful to ecosystems [3,4].

Unlike other natural penicillin antibiotics, AMX is acid-stable and difficult to hydrolysis [5]. Compared to the chemical or the physical methods for treating AMX residues, the microbial degradation methods are effective and more environmentally friendly for removing AMX residues in animal wastes. High-catalytic-activity enzyme generated by metabolic processes of microorganisms can reduce antibiotic activity by modifying the structure of antibiotic directly or indirectly [6]. Therefore, screening AMX degradation bacterial strains and optimizing the fermentation rate for these strains would potentially provide effective measures for degrading AMX residues in the environment.

The rate of removing AMX by microbial degradation is highly dependent on the bacterial strains as well as their fermentation conditions. For a given strain, minor changes in culture conditions can impact the quality and quantity of the removal of AMX antibiotic residues [7]. However, the optimization of fermentation conditions of culture media is very tedious and complicated because many factors have to be considered [8]. The Response Surface Methodology (RSM) is an effective experimental method that can identify the optimal fermentation conditions for a multi-variable system mathematically and statistically $[9,10]$. The procedure of RSM to optimize the fermentation conditions may be briefly described as follows: (i) identifying factors that significantly impact the fermentation conditions using the Plackeet-Burman (PB) design method, which can identify significant factors among a larger number of influencing variables and eliminate relatively minor factors [11,12]; (ii) determining the change step size of each significant factor that are identified by PBD using steepest ascent design, which can confirm the optimal value area quickly and economically [13]; (iii) establishing a fermentation model and determining the optimal fermentation conditions by performing the Box-Behnken design (BBD), which reduces the number of experimental runs and provides enough information for the interaction between independent variables [14]; and (iv) comparing the predicted response value directly obtained by the BBD design with the experimental response value obtained by the optimal fermentation conditions, so as to verify the adequacy of the model. The RSM has been widely used on optimizing microbial fermentation conditions to avoid the unnecessary trails and addition of excessive components in the culture medium. For example, the RSM was used for optimizing the operation parameters on the photocatalytic degradation of chloramphenicol (CAP) [15] and to investigate the effects of processing factors in the preparation of antioxidant peptides hydrolyzed from goat's milk [16]. The objective of this study was to first screen AMX-degrading bacterial strains in pig manure and then optimize the fermentation conditions for these strains to achieve high fermentation rate.

\section{Materials and Methods}

The experiments were performed to: (i) isolate efficient AMX degrading bacterial strains from pig manure using antibiotic susceptibility test and HPLC-MS/MS method; and ii) optimize the fermentation conditions of isolated bacterial strains by using the RSM method to provide a theoretical basis for industrial production of antibiotic degrading bacteria.

\subsection{Isolation and Selection of AMX-Degrading Bacterial Strains}

AMX-degrading bacterial strains were isolated and screened from the pig manure that was collected from a pig farm in Hefei, Anhui, China. This farm was selected because AMX residues were found in pig manure, which naturally led to the emergence of bacteria that feed on AMX. A total of $1000 \mathrm{~g}$ of pig manure was gathered from the farm. Collected pig manure was placed in sealed sterile bags and kept at a temperature about $-20^{\circ} \mathrm{C}$ before the experiment. Isolating and screening AMX-degrading bacterial strains were performed in three steps, namely enrichment, acclimatization and separation. The details of the steps can be found in the previously published reference [17]. 
Evaluating the degrading efficiency of bacterial strains is the key in bacterial screening. The antibiotic susceptibility test and HPLC-MS/MS methods were carried out to evaluate the degradation efficiency. The antibiotic susceptibility test qualitatively determined if an isolated bacterial strain was capable of degrading AMX. In this test, a piece of filter paper containing $10 \mu \mathrm{g}$ of AMX was applied to the surface of the Luria-Bertani (LB) agar medium $(\mathrm{NaCl}(5 \mathrm{~g} / \mathrm{L})$, yeast extract $(5 \mathrm{~g} / \mathrm{L}), 1.5 \%(\mathrm{w} / \mathrm{v})$ agar powder and tryptone $(10 \mathrm{~g} / \mathrm{L})$ at $\mathrm{pH}$ 7.0) which had been inoculated with a degradation bacterial strain. As the diffusion distance of AMX in the agar increased, the AMX concentration decreased logarithmically to a certain concentration below which the bacterium would not grow, thus forming a transparent antimicrobial circle on the filter paper. The size of this inhibition zone reflected the sensitivity of the test bacterial to AMX, i.e., the smaller the circle, the stronger resistance of bacteria to AMX. The HPLC-MS/MS method was then used on the bacteria strains that had the small inhibitory zones observed in the susceptibility tests to further evaluate quantitatively their effectiveness in degrading AMX.

A Liquid chromatography system-UPLC (I-Class)-MS (XEXO TQD) (Waters, Milford MA, US) coupled with Themo LENGEND MICRO 17R (Thermo Fisher Scientific, USA) were used in the HPLC-MS/MS evaluation. The Waters ACQUITY UPLC BEH-C18 column $(1.7 \mu \mathrm{m}, 2.1 \times 100 \mathrm{~mm}$; Waters, USA) with column temperature of $35^{\circ} \mathrm{C}$ was used. A mobile phase of $0.1 \%(\mathrm{v} / \mathrm{v})$ formic acid in water (A) and $0.1 \%(\mathrm{v} / \mathrm{v})$ formic acid in acetonitrile (B) was used, filtered through a $0.22 \mu \mathrm{m}$ membrane filter at a flow rate of $0.4 \mathrm{~mL} / \mathrm{min}$. The gradient dilution was performed as follows: $0 \mathrm{~min}, 95 \% \mathrm{~A}$; $1 \mathrm{~min}, 95 \%$ A; $3 \mathrm{~min}, 2 \%$ A; $5 \mathrm{~min}, 2 \%$ A; $5.5 \mathrm{~min}, 95 \%$ A; $8 \mathrm{~min}, 95 \%$ A. The injection volume was $1 \mu \mathrm{L}$ for both samples and standards. The mass spectrometer was used for the detection of analytes in the positive ion mode. The ionization source used a source voltage of $3.00 \mathrm{KV}$; a source temperature of $400{ }^{\circ} \mathrm{C}$; a gas flow rate of $700 \mathrm{~L} / \mathrm{Hr}$; and cone of $50 \mathrm{~L} / \mathrm{Hr}$.

The standard stock solution of AMX was prepared with ultrapure water at a concentration of $1 \mu \mathrm{g} / \mathrm{mL}$, which was then used to dilute to the following concentrations: 500, 200, 100, 50, 20, 10, 5, 2, and $1 \mathrm{ng} / \mathrm{mL}$. The culture medium samples containing the isolated bacteria strains was diluted 1000 times and centrifuged for $10 \mathrm{~min}$ at 13,000 rpm. The supernatant was removed and filtered through a $0.22 \mu \mathrm{m}$ membrane and aliquots of the supernatant were taken for HPLC-MS/MS analysis. The isolated strains that had higher degradation rates were selected for the optimization of fermentation conditions.

\subsection{Optimization of Fermentation Condition}

\subsubsection{Determination of the Growth Curve of Bacteria Strain}

The isolated bacteria strains were inoculated on LB liquid medium at $1 \%$ inoculation level and cultured at $30{ }^{\circ} \mathrm{C}$ for $24 \mathrm{~h}$ on a shaker incubator. A turbidimetric method was used to evaluate the growth curve of the bacteria [18,19], in which the growth of the bacteria was measured by the optical density of the bacterial cultural media at $600 \mathrm{~nm}\left(\mathrm{OD}_{600}\right)$ [20] using 722 ultraviolet visible light spectrophotometer (Thermo Fisher Scientific, Waltham, MA, USA) in 4, 6, 12, 15, 25, 35, 37, 40, 48, 50, 55 , and $60 \mathrm{~h}$ of culture. The bacterial growth curve was plotted as the optical density $\mathrm{OD}_{600}$ vs. the culture time.

\subsubsection{Fermentation Experiment}

The fermentation experiment was conducted to examine the effects of fermentation conditions on bacterial growth. Bacterial suspensions were inoculated on $50 \mathrm{~mL} \mathrm{LB}$ liquid medium and cultured in a shaker incubator. The range of fermentation conditions (the influencing factors and levels) was selected as follows: the fermentation time $(20,30,40,50$, and $60 \mathrm{~h})$, temperature $(20,25,30,35$, and $\left.40{ }^{\circ} \mathrm{C}\right)$, the inoculum level $(0.5 \%, 1 \%, 1.5 \%, 2.0 \%$, and $2.5 \%)$, the shaker rotation speed $(110,120,130$, 140 , and $150 \mathrm{rpm})$, and $\mathrm{pH}(5,6,7,8$, and 9) [21,22]. 


\subsubsection{Selection of Significant Variables by Plackett-Burman Design (PBD)}

Based on the data from the fermentation experiment, the Plackeet-Burman design (PBD) was used to screen the factors that have the most significant influence among a set of factors by using a minimum number of tests [11]. It should be noted that this design is not focused on the interrelationship between factors, but merely on the significant effects of these factors [12]. Specifically, the effects of five parameters that defined the culture condition on the $\mathrm{OD}_{600}$ value of bacterial cultures were investigated. The number of tests selected was $\mathrm{N}=12$, with five parameters $\mathrm{X}_{1}, \mathrm{X}_{2}, \mathrm{X}_{3}, \mathrm{X}_{4}$, and $\mathrm{X}_{5}$ representing the fermentation time, the temperature, the inoculum level, the shaker speed, and $\mathrm{pH}$, respectively. The high $(+1)$ and low $(-1)$ levels of these parameters are shown in Table 1, with the high level being 1.25 times the low level. The regression analysis was carried out using the software MINITAB 17.0 (Minitab, LLC, State College PA, USA) to assess the statistical significance.

Table 1. Factors and levels of Plackett-Burman design (PBD).

\begin{tabular}{ccc}
\hline & \multicolumn{2}{c}{ Level } \\
\cline { 2 - 3 } Parameters & $\mathbf{- 1}$ & $\mathbf{1}$ \\
\hline $\mathrm{X}_{1}$ Time $(\mathrm{h})$ & 40 & 50 \\
$\mathrm{X}_{2}$ Temperature $\left({ }^{\circ} \mathrm{C}\right)$ & 30 & 37.5 \\
$\mathrm{X}_{3}$ Inoculum level $(\%)$ & 1 & 1.25 \\
$\mathrm{X}_{4}$ Shaker speed $(\mathrm{rpm})$ & 120 & 150 \\
$\mathrm{X}_{5} \mathrm{pH}$ & 6 & 7.5 \\
\hline
\end{tabular}

\subsubsection{Steepest Ascent Design (SAD)}

Three most significant influencing variables selected by the PBD were further analyzed by the steepest ascent design (SAD) to design the next experiment (selecting the rage of parameters) to further optimize the fermentation condition. The steepest ascent design uses the gradient direction of the experimental data as the climbing direction, and the change step size is determined according to the effect value of each factor, which can approach the target area quickly and economically [13].

\subsubsection{Box-Benhnken Design (BBD)}

The three significant factors and the best level of these factors identified after PBD and SAD were further optimized using Box-Behnken response surface design (BBD) [14]. This design coupled with the response surface methodology (RSM) is one of the most commonly used methods for process optimization with minimal experimental requirements [23]. In this design, the optical density $\left(\mathrm{OD}_{600}\right)$ value (growth) of bacteria was considered as the response value and the three identified significant variables the independent variables. Data analysis and experimental design were performed for each single factor using Design-Expert (Version 8.0.6, Stat-Ease Inc., Minneapolis, MN, USA).

Based on the BBD, a set of 12 tests were performed and a second-order polynomial model was used to fit to the data to generate a prediction model for the optimal fermentation condition.

$$
Y=\alpha 0+\alpha 1 X m+\alpha 2 X n+\alpha 3 X p+\alpha 11 X m 2+\alpha 22 X n 2+\alpha 33 X p 2+\alpha 12 X m X n+\alpha 13 X m X p+\alpha 23 X n X p
$$

where $Y$ is the response (bacterial growth), $X_{m}, X_{n}$ and $X_{P}$ are the three most significant parameters identified by the PBS among the five factors that were tested in the first set of fermentation tests (Table 1); $\alpha_{0}$ is the offset term, and $\alpha_{\mathrm{i}}, \alpha_{\mathrm{ii}}$ and $\alpha_{\mathrm{ij}}$ are the regression coefficients of the first-order main effect, the second main effect, and interaction effect, respectively.

\subsubsection{Verification}

To verify the effectiveness of the three-step optimization procedure (PBD-SAD-BBD), three separate tests were carried out according to the optimal fermentation conditions identified through the BBD experiments. The result was compared to the values predicted by the optimization Equation (1). 


\section{Results and Discussion}

\subsection{Isolation and Preliminary Screening of AMX-Degrading Bacterial Strains from the Pig Manure}

A total of six AMX-degrading bacterial strains (denoted as AMX-1, AMX-2, AMX-3, AMX-4, AMX-5, AMX-6) capable of growing on AMX as sole carbon and energy source were isolated from the pig manure. From the antibiotic susceptibility test, the inhibitory zone diameters of AMX-1, AMX-2, AMX-3, AMX-4, AMX-5, AMX-6 were determined to be $6.52 \pm 0.28 \mathrm{~mm}, 16.85 \pm 2.13 \mathrm{~mm}$, $8.93 \pm 1.24 \mathrm{~mm}, 21.52 \pm 1.87 \mathrm{~mm}, 36.87 \pm 1.48 \mathrm{~mm}$ and $10.75 \pm 1.24 \mathrm{~mm}$ (Mean \pm standard deviation, SD) (Figure 1), respectively. The inhibitory zone diameters of AMX-2, AMX-4 and AMX-5 were significantly larger than that of the other three strains (AMX-1, AMX-3, and AMX-6) $(P<0.05)$, and there were no statistically significant differences among AMX-1, AMX-3, and AMX-6. Therefore, AMX-2, AMX-4 and AMX-5 were considered to be less effective in degrading AMX antibiotic, and the other three bacterial strains (AMX-1, AMX-3 and AMX-6) were selected for further quantitative evaluation by HPLC-MS/MS.
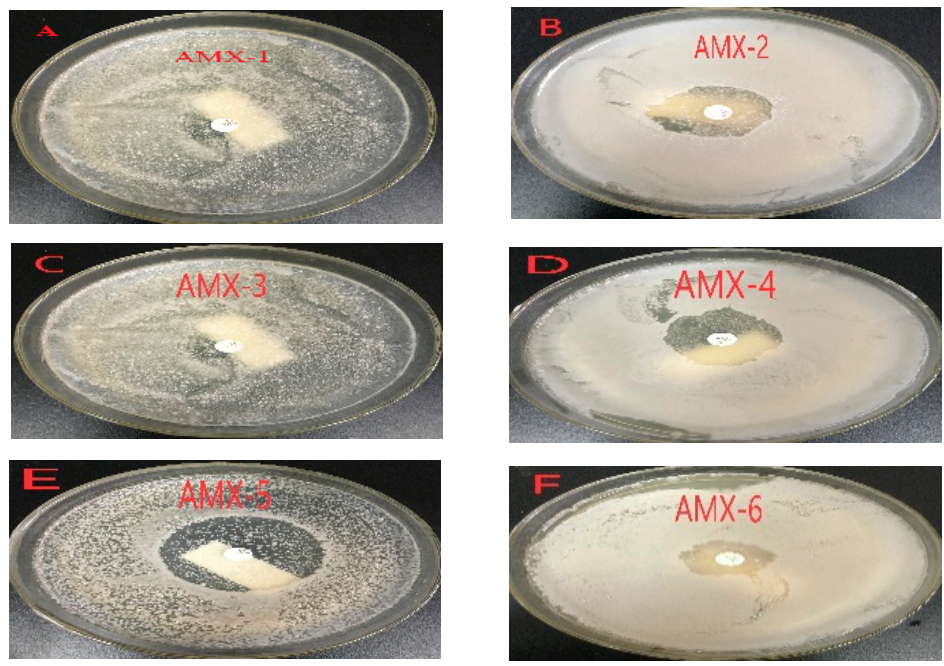

Figure 1. Results of amoxicillin (AMX) susceptibility test of six bacterial strain isolated from pig manure: (A) AMX-1; (B) AMX-2; (C) AMX-3; (D) AMX-4; (E) AMX-5; (F) AMX-6.

\subsection{Screening by HPLC-MS/MS}

The AMX degradation rates of strains AMX-1, AMX-3, and AMX-6 measured by using HPLC-MS/MS, along with the blank control, are summarized in Figures 2 and 3 and Table 2.

Table 2. Regression equation model analysis.

\begin{tabular}{ccccc}
\hline Compound Name & Linear Range & Regression Equation & $\mathbf{R}^{\mathbf{2}}$ & Retention Time (min) \\
\hline AMX & $1-1000 \mathrm{ng} / \mathrm{mL}$ & $\mathrm{Y}=39.31 \mathrm{X}-1.71$ & 0.9995 & 1.87 \\
\hline
\end{tabular}



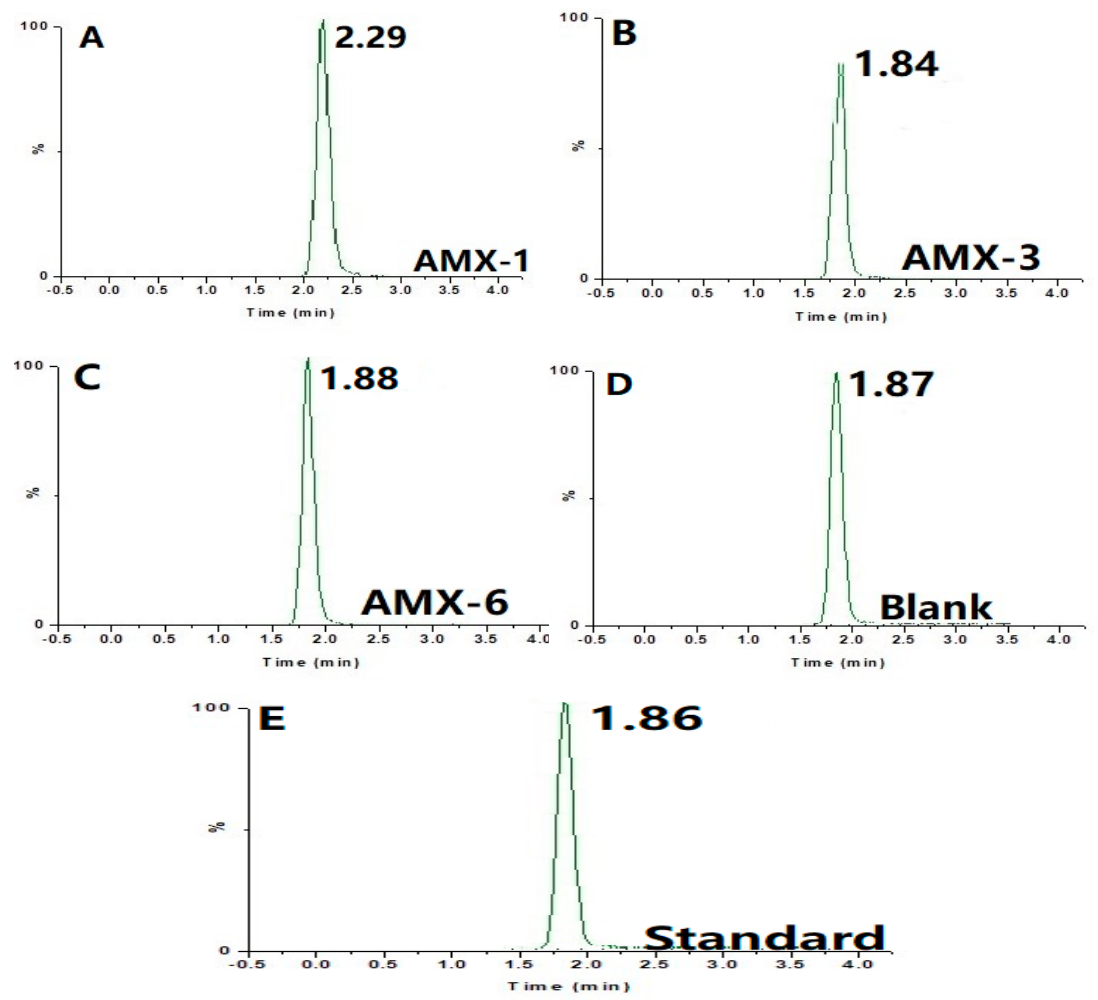

Figure 2. Results of HPLC-MS/MS analysis 90 min after inoculation of (A) strain AMX-1, (B) AMX-3, (C) AMX-6, (D) blank samples, (E) standard (non-inoculated) sample of AMX of $100 \mathrm{mg} / \mathrm{L}$.

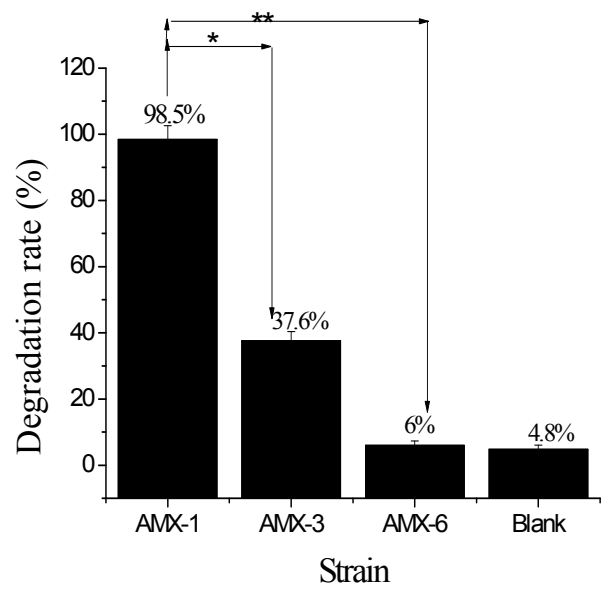

Figure 3. Comparison of AMX degradation by isolated bacterial strains. ${ }^{*}$ indicates a significant difference at $p<0.05$, and ${ }^{* *}$ significant difference at $p<0.01$.

The peak time of non-inoculated AMX standard solution detected by HPLC-MS/MS was $1.86 \mathrm{~min}$ (Figure 2E). Ninety (90) min after inoculation, AMX was still detected in the solutions of strains AMX-3 and AMX-6, but not in AMX-1 (a new unknown substance with an absorption peak at 2.29 was detected, Figure 2A). In other words, AMX was degraded and new degradation products were produced under the action of AMX-1 strain [24]. Regression analysis yielded a linear relationship between the concentration of $A M X$ and the corresponding peak: $Y=39.31 X-1.71, R^{2}=0.999$. Using this relationship, the degradation rate by AMX-1 was calculated be to $98.5 \%$, which was significantly higher than the other two strain (Figure 3). Therefore, AMX-1 bacterial strain was selected for the optimization of fermentation conditions. 


\subsection{Growth Curve of AMX-1}

The growth of AMX-1 strain roughly followed a typical "S" curve (Figure 4). A lag period occurred from 0 to $25 \mathrm{~h}$, followed by a logarithmic growth period from 25 to $50 \mathrm{~h}$, where the number of live bacteria increased rapidly and the maximum growth rate was reached. The growth reached a stable state after $55 \mathrm{~h}$, which indicated the total number of living bacteria reached the maximum.

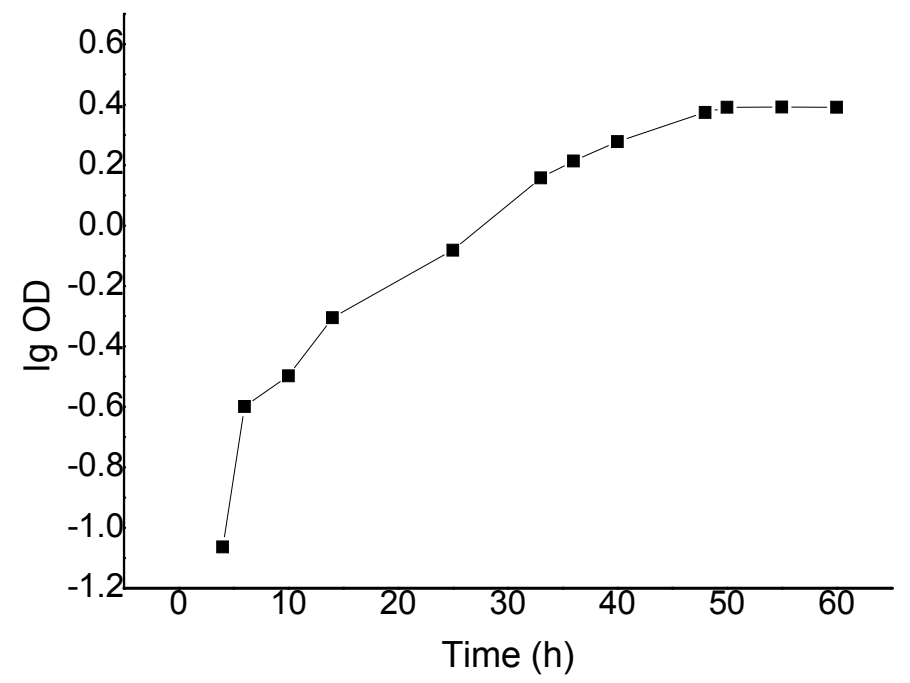

Figure 4. Growth curve of strain AMX-1.

\subsection{Effects of Individual Factors}

The measured optical density $\left(\mathrm{OD}_{600}\right)$, representing the bacterial growth rate, increased first with temperature until about $35^{\circ} \mathrm{C}$ and then decreased, with the quickest increase between 25 and $30{ }^{\circ} \mathrm{C}$ (Figure 5a). It was interesting to note that when the temperature was $40{ }^{\circ} \mathrm{C}$, the $\mathrm{OD}_{600}$ value was even lower than that at $30^{\circ} \mathrm{C}$. It was clear that the optimal temperature range for AMX-1 growth was $30-35{ }^{\circ} \mathrm{C}$, while other condition parameters were at the 0-level as described in Table 1.

The bacterial growth increased with the inoculum level rapidly between $1.0-1.5 \%(\mathrm{v} / \mathrm{v})$, reaching the maximum at about $1.5 \%(\mathrm{v} / \mathrm{v})$ (Figure $5 \mathrm{~b})$. Further increase in inoculum level resulted in a slower growth because oxygen and nutrients available to the bacteria in the medium became limiting and accompanied by bacterial proliferation, affecting the production of primary and secondary metabolites [25].

The shaker speed was related to the dissolved oxygen content in the culture solution $[26,27]$. Through the vibration of the shaker, the oxygen in the air was continuously dissolved into the culture solution for the bacteria. The bacterial growth increased with the rotation speed of the shaker linearly, indicating that the bacterial growth was closely related to the aeration level (Figure 5c), and that the bacterial strain was aerobic.

The bacterial growth increased with time and reached a maximum value at $50 \mathrm{~h}$ (Figure $5 \mathrm{~d}$ ). The growth stayed almost constant when the time was extended to $60 \mathrm{~h}$, indicating that the bacterial growth had entered a stable state after $50 \mathrm{~h}$. The possible reasons were: (i) depletion of nutrients in the medium; (ii) imbalance of nutrients, such as the inappropriate $\mathrm{C} / \mathrm{N}$ ratio; (iii) accumulation of harmful metabolites such as acid, alcohol, toxins, or hydrogen peroxide $\left(\mathrm{H}_{2} \mathrm{O}_{2}\right)$; and (iv) physical and chemical conditions such as $\mathrm{pH}$ and redox potential becoming less suitable for the bacteria [28,29]. 

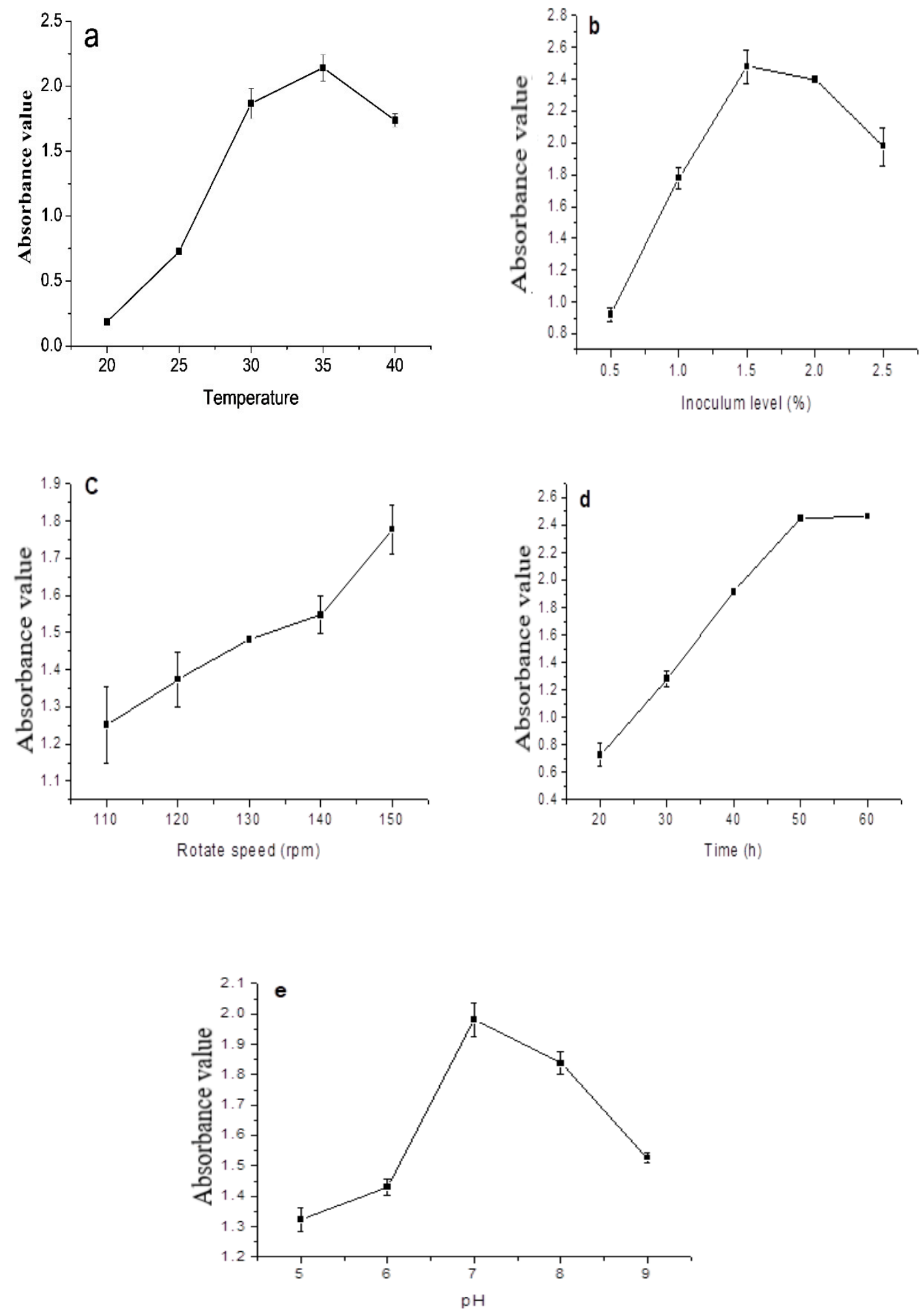

Figure 5. Results of the single-factor test. Effect of (a) temperature, (b) inoculum level, (c) rotate speed, (d) time, and (e) $\mathrm{pH}$ on the optical density $\left(\mathrm{OD}_{600}\right)$ value of bacterial.

The bacterial strain grew well only in a narrow range of $\mathrm{pH}$, with the optimal $\mathrm{pH}$ around 7 (Figure 5e). In the acidic or alkaline environment with a $\mathrm{pH}$ of 5 or 10 , the $\mathrm{OD}_{600}$ value of this strain decreased significantly, which indicated that the initial $\mathrm{pH}$ value could significantly affect the growth of this strain. 


\subsection{Plackett-Burman Design (PBD) Screening}

The purpose of PBD was to identify which conditions of fermentation had a significant effect on the growth of the AMX-1 strain. The optical density OD $_{600}$ ranged from 1.589 (run 7) to 1.899 (run 9), as measured in the fermentation experiment (Table 3). The results of statistical analysis on the main effect are presented in Table 4 . The significance of each factor was assessed using the $P$-value at the significance level of 0.05 .

Table 3. Design and test results of Plackett-Burman.

\begin{tabular}{ccccccc}
\hline Run Order & $\mathbf{X}_{\mathbf{1}}$ Time (h) & $\begin{array}{c}\mathbf{X}_{\mathbf{2}} \text { Temperature } \\
\left({ }^{\circ} \mathbf{C}\right)\end{array}$ & $\begin{array}{c}\mathbf{X}_{\mathbf{3}} \text { Inoculum } \\
\text { Level }\end{array}$ & $\begin{array}{c}\mathbf{X}_{\mathbf{4}} \text { Rotate Speed } \\
(\mathbf{r p m})\end{array}$ & $\mathbf{X}_{\mathbf{5}} \mathbf{p H}$ & Optical Density \\
\hline 1 & 50 & 37.5 & 1.25 & 120 & 7.5 & 1.77 \\
2 & 40 & 30 & 1.25 & 150 & 7.5 & 1.66 \\
3 & 50 & 37.5 & 1 & 150 & 6 & 1.839 \\
4 & 50 & 37.5 & 1 & 150 & 7.5 & 1.899 \\
5 & 50 & 30 & 1.25 & 150 & 6 & 1.609 \\
6 & 40 & 37.5 & 1.25 & 120 & 7.5 & 1.599 \\
7 & 40 & 30 & 1 & 120 & 6 & 1.589 \\
8 & 50 & 30 & 1.25 & 120 & 6 & 1.678 \\
9 & 50 & 30 & 1 & 120 & 7.5 & 1.899 \\
10 & 40 & 37.5 & 1 & 120 & 6 & 1.709 \\
11 & 40 & 37.5 & 1.25 & 150 & 6 & 1.649 \\
12 & 40 & 30 & 1 & 150 & 7.5 & 1.729 \\
\hline
\end{tabular}

Table 4. Analysis of variance in Plackett-Burman.

\begin{tabular}{cccccccc}
\hline Source & Sum of Squares & df & Mean Squares & F-Value & $\boldsymbol{P}$-Value & $\begin{array}{c}\text { Coefficient } \\
\text { Estimate }\end{array}$ & $\begin{array}{c}\text { Significance } \\
\text { Ranking }\end{array}$ \\
\hline Model & 0.1173 & 5 & 0.0234 & 7.79 & 0.013 & & \\
X $_{1}$ & 0.048 & 1 & 0.048 & 15.92 & 0.007 & 0.0633 & 1 \\
X $_{2}$ & 0.0076 & 1 & 0.0076 & 2.5 & 0.165 & 0.0251 & 4 \\
$X_{3}$ & 0.0407 & 1 & 0.0407 & 13.5 & 0.01 & -0.0583 & 2 \\
$X_{4}$ & 0.0016 & 1 & 0.0017 & 0.55 & 0.487 & 0.0118 & 5 \\
$X_{5}$ & 0.0194 & 1 & 0.0194 & 6.45 & 0.044 & 0.0403 & 3 \\
Residual & 0.0181 & 6 & 0.003 & & & & \\
Cor total & 0.1354 & 11 & & & & & \\
\hline
\end{tabular}

The significance of the five variables in terms of their effects on the optical density $\left(\mathrm{OD}_{600}\right)$ was ranked as: $\mathrm{X}_{1}$ (Time) $>\mathrm{X}_{3}$ (Inoculum level) $>\mathrm{X}_{5}(\mathrm{pH})>\mathrm{X}_{2}$ (Temperature) $>\mathrm{X}_{4}$ (Rotation speed). Among them, the effects of the fermentation time, inoculum level and $\mathrm{pH}$ were statistically significant $(P<0.05)$. Therefore, these three variables were considered as the significant factors in the next experiment.

\subsection{Steepest Ascent Design}

The Coefficient Estimate of $X_{1}, X_{3}$ and $X_{5}$ presented in Table 4 indicated that the fermentation time and the initial $\mathrm{pH}$ value exhibited positive effects and the inoculum level exhibited a negative effect. Based on these observations, the directions of the gradients for $\mathrm{X}_{1}, \mathrm{X}_{2}$, and $\mathrm{X}_{4}$ in the steepest ascent design were determined (Table 5). Specifically, the time and $\mathrm{pH}$ were gradually increased, while the inoculum level was decreased. The corresponding optical density $\left(\mathrm{OD}_{600}\right)$ value first increased and then decreased (Table 5), with the maximum $\mathrm{OD}_{600}$ at the fermentation time $50 \mathrm{~h}, \mathrm{pH}$ 6.5, and inoculum level $1.5 \%(\mathrm{v} / \mathrm{v})$. 
Table 5. The design and results of steepest ascent test.

\begin{tabular}{cccccc}
\hline Test & Step Size & $\mathbf{X}_{\mathbf{1}}$ & $\mathbf{X}_{\mathbf{3}}$ & $\mathbf{X}_{\mathbf{5}}$ & $\mathbf{O D}_{\mathbf{6 0 0}}$ \\
\hline 1 & $\mathrm{X}$ & $30 \mathrm{~h}$ & $2.5 \%(\mathrm{v} / \mathrm{v})$ & 5.5 & 1.48 \\
2 & $\mathrm{X}+\Delta \mathrm{X}_{\mathrm{i}}$ & $40 \mathrm{~h}$ & $2.0 \%(\mathrm{v} / \mathrm{v})$ & 6.0 & 1.63 \\
3 & $\mathrm{X}+\Delta 2 \mathrm{X}_{\mathrm{i}}$ & $50 \mathrm{~h}$ & $1.5 \%(\mathrm{v} / \mathrm{v})$ & 6.5 & 1.89 \\
4 & $\mathrm{X}+\Delta 3 \mathrm{X}_{\mathrm{i}}$ & $60 \mathrm{~h}$ & $1.0 \%(\mathrm{v} / \mathrm{v})$ & 7.0 & 1.74 \\
5 & $\mathrm{X}+\Delta 4 \mathrm{X}_{\mathrm{i}}$ & $70 \mathrm{~h}$ & $0.5 \%(\mathrm{v} / \mathrm{v})$ & 7.5 & 1.65 \\
\hline \multicolumn{6}{c}{ Note: $\Delta \mathrm{X}_{1}=+10 \mathrm{~h}, \Delta \mathrm{X}_{3}=-0.5 \%(\mathrm{v} / \mathrm{v}), \Delta \mathrm{X}_{5}=+0.5}$.
\end{tabular}

\subsection{Optimization: Box-Behnken Design}

Based on the data in Table 5 (the maximum $\mathrm{OD}_{600}$ at fermentation time $\mathrm{X}_{1}=50 \mathrm{~h}$, the inoculum level $\mathrm{X}_{3}=1.5 \%(\mathrm{v} / \mathrm{v})$, and $\mathrm{pH} \mathrm{X}_{5}=6.5$, a BBD design was proposed to further refine the optimal fermentation condition (Table 6). The corresponding experimental results based on this BBD are shown in Table 7.

Table 6. The factors levels in BBD.

\begin{tabular}{cccc}
\hline Level. & $\mathbf{X}_{\mathbf{1}}$ (Time) $(\mathbf{h})$ & $\mathbf{X}_{\mathbf{3}}$ (Inoculum Level) $\mathbf{( \% )}$ & $\mathbf{X}_{\mathbf{5}}(\mathbf{p H})$ \\
\hline-1 & 40 & 1.00 & 6.00 \\
0 & 50 & 1.5 & 6.5 \\
1 & 60 & 2.0 & 7.0 \\
\hline
\end{tabular}

Table 7. Experimental results of Box-Behnken Design.

\begin{tabular}{ccccc}
\hline Test & $\mathbf{X}_{\mathbf{1}}$ Time (h) & $\mathbf{X}_{\mathbf{3}}$ Inoculum Level (\%) & $\mathbf{X}_{\mathbf{5}} \mathbf{p H}$ & Response Value $\left.\mathbf{( O D}_{\mathbf{6 0 0}}\right)$ \\
\hline 1 & -1 & 0 & 1 & 2.54 \\
2 & 0 & -1 & 1 & 2.94 \\
3 & 0 & 0 & 0 & 2.27 \\
4 & 1 & 1 & 0 & 2.73 \\
5 & -1 & 1 & 0 & 2.4 \\
6 & 1 & -1 & 0 & 1.96 \\
7 & 0 & 0 & 0 & 2.57 \\
8 & 1 & 0 & 1 & 2.51 \\
9 & 0 & -1 & -1 & 1.8 \\
10 & 0 & 1 & 1 & 2.80 \\
11 & 1 & 0 & -1 & 1.36 \\
12 & 0 & 0 & 0 & 2.82 \\
13 & -1 & 0 & -1 & 1.30 \\
14 & -1 & -1 & 0 & 2.27 \\
15 & 0 & 0 & 0 & 2.82 \\
16 & 0 & 1 & -1 & 1.97 \\
17 & 0 & 0 & 0 & 2.60 \\
\hline
\end{tabular}

Design-Expert 8.0 was used to analyze the data in Table 7 and the following regression equation was obtained:

$$
Y=2.616+0.00625 X_{1}+0.11625 X_{3}+0.545 X_{5}+0.16 X_{1} \times X_{3}-0.0225 X_{3} \times X_{5}-0.363 X_{12}+0.087 X_{32}-0.3225 X_{52}\left(R^{2}=0.9195\right)
$$

where $\mathrm{Y}$ is $\mathrm{OD}_{600}$ (the response value), $\mathrm{X}_{1}$ is time (hr), $\mathrm{X}_{3}$ is the inoculum level (\%), and $\mathrm{X}_{5}$ is the initial $\mathrm{pH}$ value.

The details of regression analysis are summarized in Table 8. 
Table 8. Analysis of variance of regression.

\begin{tabular}{cccccc}
\hline Source & Sum of Squares & $\mathbf{d f}$ & Mean Square & F-Value & $\boldsymbol{P}$-Value \\
\hline$X_{1}$ & 0.0003125 & 1 & 0.0003125 & 0.006794 & 0.9366 \\
$X_{3}$ & 0.11 & 1 & 0.11 & 2.35 & 0.1691 \\
$X_{5}$ & 2.38 & 1 & 2.38 & 51.66 & 0.0002 \\
$X_{1} X_{3}$ & 0.1 & 1 & 0.1 & 2.23 & 0.1793 \\
$X_{1} X_{5}$ & 0.002025 & 1 & 0.002525 & 0.044 & 0.8398 \\
$X_{3} X_{5}$ & 0.024 & 1 & 0.024 & 0.52 & 0.4933 \\
$X_{12}$ & 0.55 & 1 & 0.55 & 12.06 & 0.0104 \\
$X_{32}$ & 0.032 & 1 & 0.032 & 0.69 & 0.4327 \\
$X_{52}$ & 0.45 & 1 & 0.45 & 9.7 & 0.017 \\
Model & 3.68 & 9 & 0.41 & 8.89 & 0.0044 \\
Lack of Fit & 0.12 & 3 & 0.039 & 0.76 & 0.5733 \\
Pure Error & 0.21 & 4 & 0.051 & & \\
Cor Total & 4 & 16 & & & \\
\hline
\end{tabular}

Note: The $P$-value less than 0.001 for the difference is extremely significant; the $P$-value less than 0.01 is highly significant; the $P$-value less than 0.05 is significant.

The $P$-value for the overall model was 0.0044 , which demonstrated that the quadratic equation model was highly significant [30]. Based on the $P$-values associated with the three factors, their influences on the optical density $\left(\mathrm{OD}_{600}\right)$ of bacterial growth were ranked as: $\mathrm{X}_{5}(\mathrm{pH})>\mathrm{X}_{3}$ (Inoculum level) $>X_{1}$ (Time). The $P$-value for misfitting was 0.5733 , indicating that the misfitting term was insignificant relative to the absolute error, and the misclassification is not significant. At the same time, the adjusted determination coefficient (Adj R-squared, Table 9) $(0.82>0.80)$ and coefficient of variance $(\mathrm{CV} \%)$ was 9.19 , which further indicated that the multivariate regression relationship between the dependent variable and the all independent variables was significant [31]. In other words, the regression equation was adequate in predicting the optical density $\left(\mathrm{OD}_{600}\right)$ under different fermentation conditions [32] (Figure 6).

Table 9. Statistical significance.

\begin{tabular}{cc}
\hline Model Terms & Results \\
\hline Std. dev. & 0.21 \\
Mean & 2.33 \\
\%CV & 9.19 \\
PRESS & 2.19 \\
R-squared & 0.9195 \\
Adj R-squared & 0.8161 \\
Adeq precision & 9.772 \\
\hline
\end{tabular}
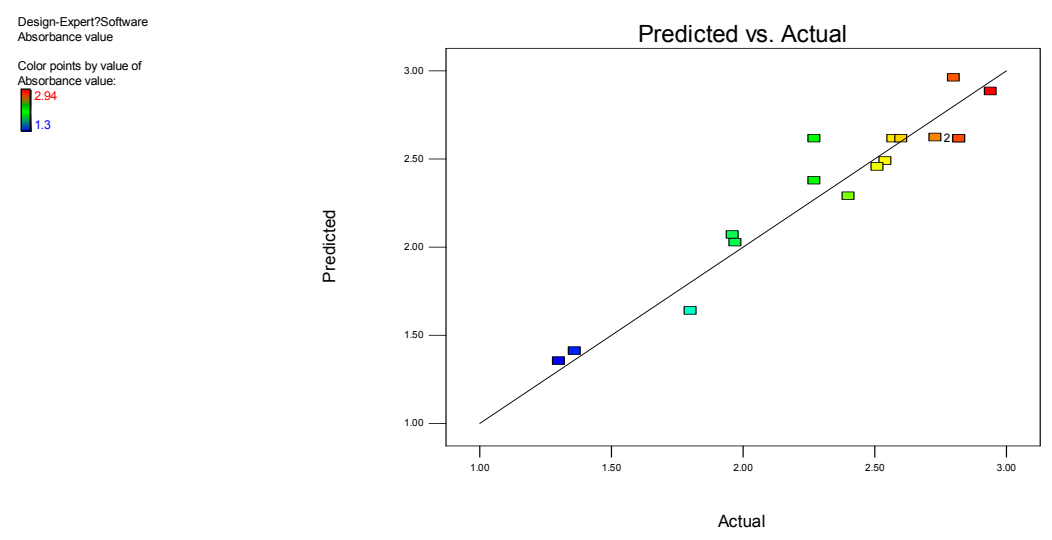

Figure 6. Internally studentized residuals. 
Determination of Optimal Fermentation Condition

The response surface contour maps for the factors were generated based on the regression Equation (2) to search for the optimal fermentation condition (Figure 7).

a

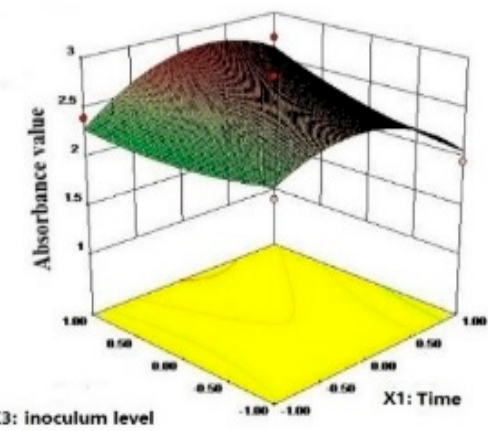

C

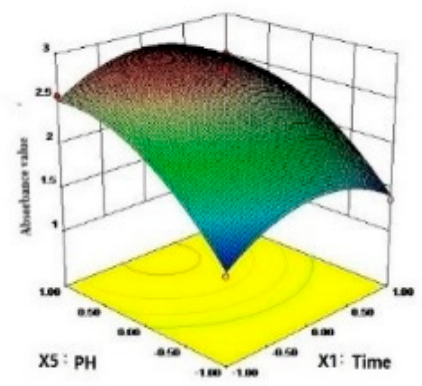

e

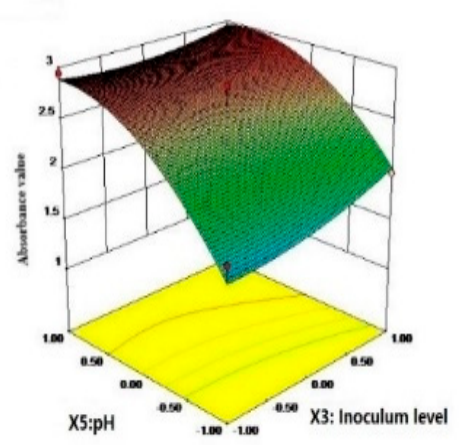

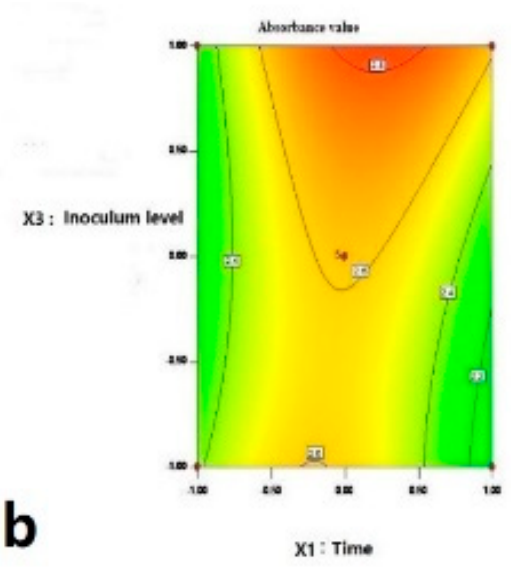
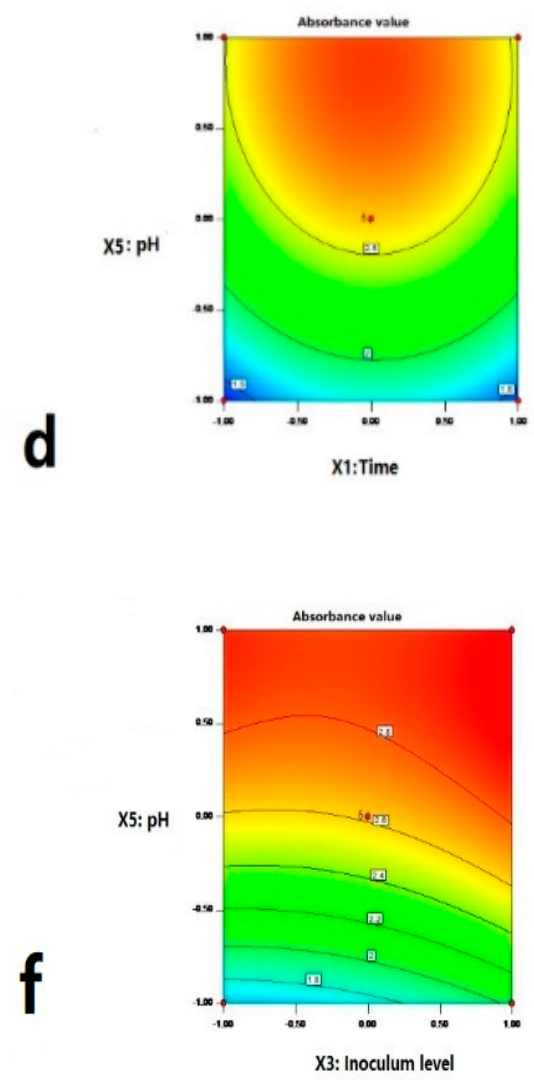

Figure 7. Response surface plots (3D) and contour plots (2D) for the effect of fermentation condition on $\mathrm{OD}_{600} \cdot(\mathbf{a}, \mathbf{b})$ Effects of fermentation time and inoculum level; $(\mathbf{c}, \mathbf{d})$ effects of fermentation time and $\mathrm{pH}$; and $(\mathbf{e}, \mathbf{f})$ effects of inoculum level and $\mathrm{pH}$.

The profiles of the response surfaces between fermentation time and inoculum level, fermentation time and $\mathrm{pH}$, inoculum level and $\mathrm{pH}$ were all convex with an open downward direction, indicating a parabolic relationship between the $\mathrm{OD}_{600}$ value and the three factors of fermentation time, inoculum level and $\mathrm{pH}$ [33].The surface plots showed the interactive effects of the three significant fermentation factors on the bacterial growth. Figure $7 \mathrm{~b}, \mathrm{c}$ clearly demonstrates that the $\mathrm{OD}_{600}$ increased with $\mathrm{pH}$, 
with the optimal $\mathrm{pH}$ value of 7.00 (Figure 7a) [29]. Comparing Figure 7a-c indicates that the $\mathrm{pH}$ also had the most significant effect on the bacterial growth among the three variables as the response surface curvatures were smaller (Figure $7 \mathrm{a}$ ). Figure $7 \mathrm{~b}, \mathrm{~d}$, and $\mathrm{m}$ shows that the contour lines were circular, indicating the interaction of these three factors was not obvious [29,31]. Overall, the optimum fermentation condition for the screened bacterial strain was predicted to be: the fermentation time of $52.1 \mathrm{~h}$, the inoculum level of $2 \%$, and $\mathrm{pH}$ of 6.855 , and this condition resulted in a predicted $\mathrm{OD}_{600}$ value of 3.00 .

\subsection{Experimental Verification}

To verify the prediction model (Equation (2)), the predicted optimal fermentation condition (fermentation time $\mathrm{X}_{1}=52 \mathrm{~h}$, the inoculum level $\mathrm{X}_{3}=2 \%$, and $\mathrm{pH} \mathrm{X}_{5}=6.9$ ) was used to conduct a set of tests to measure $\mathrm{OD}_{600}$. The average OD600 of five replicates was 2.94 with a standard deviation of 0.045 . The difference between the predicted and measured values was about $2 \%$, indicating that the model was adequate in predicting the optimal fermentation condition.

\section{Conclusions}

An effective Amoxicillin (AMX) degrading bacteria strain was successfully isolated and screened from pig manure through the antibiotic susceptibility testing and HPLC-MS/MS. A three-step procedure was developed to optimize the fermentation conditions for this screened bacteria strain. In the developed optimization procedure, the Plackett-Burman design (PBD) was first used to select most significant parameters; the steepest ascent design (SAD) was then used to define the gradient direction for the Box-Benhnken design (BBD); and finally the BBD with the response surface method (RSM) was used to refine the optimal fermentation condition, and a predictive model of quadratic polynomial was developed. It was found that among the five factors that defined the fermentation conditions, namely the inoculum level, the fermentation time, temperature, $\mathrm{pH}$ and shaker speed, three had significant effect on the growth of screened bacterial strain in the following order: $\mathrm{pH}$, the fermentation time, and the inoculum level. The determined optimal fermentation condition was: $\mathrm{pH} 6.9$, the fermentation time $52.1 \mathrm{~h}$, and the inoculum level $2 \%$. The proposed optimization process increased the bacterial growth rate by $67.6 \%$. The proposed quadratic polynomial model adequately (within $2 \%$ ) predicted the optimal fermentation condition.

Author Contributions: Conceptualization, M.L. and X.Y.; methodology, X.Y., and H.L.; software, Z.H. and X.L.; formal analysis, P.G.; investigation, X.Y.; writing—original draft preparation, X.Y.; writing-review and editing, X.Y. and Q.Z.; funding acquisition, M.L. All authors have read and agreed to the published version of the manuscript.

Funding: This work was funded by the Project: Development and demonstration of key technologies and equipment for utilization of straws and animal mortalities (201904a06020041). Funding program: Anhui Priority Research and Development Strategies.

Conflicts of Interest: All authors declare that they have no conflict of interest.

\section{References}

1. Demirezen, D.A.; Yıldız, Y.Ş.; Yılmaz, D.D. Amoxicillin degradation using green synthesized iron oxide nanoparticles: Kinetics and mechanism analysis. Environ. Nanotechnol. Monit. Manag. 2019, 11, 100219. [CrossRef]

2. Zhang, Y.; Xiao, Y.; Zhong, Y.; Lim, T.-T. Comparison of amoxicillin photodegradation in the UV/H2O2 and UV/persulfate systems: Reaction kinetics, degradation pathways, and antibacterial activity. Chem. Eng. J. 2019, 372, 420-428. [CrossRef]

3. Martínez, J.L. Environmental pollution by antibiotics and by antibiotic resistance determinants. Environ. Pollut. 2009, 157, 2893-2902. [CrossRef] [PubMed] 
4. $\quad$ Ouyang, W.-Y.; Su, J.-Q.; Richnow, H.H.; Adrian, L. Identification of dominant sulfamethoxazole-degraders in pig farm-impacted soil by DNA and protein stable isotope probing. Environ. Int. 2019, 126, 118-126. [CrossRef] [PubMed]

5. Rizzo, L.; Meric, S.; Guida, M.; Kassinos, D.; Belgiorno, V. Heterogenous photocatalytic degradation kinetics and detoxification of an urban wastewater treatment plant effluent contaminated with pharmaceuticals. Water Res. 2018, 43, 4070-4078. [CrossRef]

6. Li, B.; Zhang, T. Biodegradation and Adsorption of Antibiotics in the Activated Sludge Process. Environ. Sci. Technol. 2010, 44, 3468-3473. [CrossRef]

7. Leung, H.; Minh, T.; Murphy, M.; Lam, J.C.; So, M.; Martin, M.; Lam, P.K.; Richardson, B.; Lam, K.S.P. Distribution, fate and risk assessment of antibiotics in sewage treatment plants in Hong Kong, South China. Environ. Int. 2012, 42,1-9. [CrossRef]

8. Navarrete-Bolaños, J.L.; Téllez-Martínez, M.G.; Miranda-López, R.; Jiménez-Islas, H. An experimental strategy validated to design cost-effective culture media based on response surface methodology. Prep. Biochem. Biotechnol. 2017, 47, 578-588. [CrossRef]

9. Ahmad, A.; Alkharfy, K.M.; Wani, T.A.; Raish, M. Application of Box-Behnken design for ultrasonic-assisted extraction of polysaccharides from Paeonia emodi. Int. J. Boil Macromol. 2015, 72, 990-997. [CrossRef]

10. Singh, J.; Kaur, P. Optimization of process parameters for cellulase production from Bacillus sp. JS14 in solid substrate fermentation using response surface methodology. Braz. Arch. Boil Technol. 2012, 55, 505-512. [CrossRef]

11. Plackett, R.L.; Burman, J.P. The design of optimum multifactorial experiments. Biometrics 1944, 33, 305-325. [CrossRef]

12. Shu, G.; Mei, S.; Zhang, Q.; Xin, N.; Chen, H. Application of the Plackett-Burman design to determine the main factors affecting the anti-oxidative activity of goat's milk casein hydrolyzed by Alcalase and papain. Acta Sci. Pol. Technol. Aliment. 2018, 17, 257-266. [CrossRef] [PubMed]

13. Chen, H.; Niu, J.; Qin, T.; Ma, Q.; Wang, L.; Shu, G. Optimization of the medium for Lactobacillus acidophilus by Plackett-Burman and steepest ascent experiment. Acta Sci. Pol. Technol. Aliment. 2015, 14, 227-232. [CrossRef] [PubMed]

14. Cui, F.; Zhao, L. Optimization of Xylanase Production from Penicillium sp.WX-Z1 by a Two-Step Statistical Strategy: Plackett-Burman and Box-Behnken Experimental Design. Int. J. Mol. Sci. 2012, 13, 10630-10646. [CrossRef]

15. Zhang, J.; Fu, D.; Xu, Y.; Liu, C. Optimization of parameters on photocatalytic degradation of chloramphenicol using $\mathrm{TiO}_{2}$ as photocatalyist by response surface methodology. J. Environ. Sci. 2010, 22, 1281-1289. [CrossRef]

16. Wang, Q.F.; Zhu, P.L.; Xia, Z.M.; Wang, Y.; Zeng, Y.; Hou, Y. Screening and degradation properties of three kinds of agricultural antibiotics degrading fungi. J. Agric. Resour. Environ. 2018, 35, 533-539. [CrossRef]

17. Yang, X.J.; Li, M.; Guo, P.P.; Li, H.L.; Hu, Z.L.; Liu, X.W.; Zhang, Q. Isolation, Screening, and Characterization of Antibiotic-Degrading Bacteria for Penicillin V Potassium (PVK) from Soil on a Pig Farm. Int. J. Environ. Res. Public Health 2019, 16, 2166. [CrossRef]

18. Ignatova, T.; Iliev, I.; Kirilov, N.; Vassileva, T.; Dalgalarrondo, M.; Haertlé, T.; Chobert, J.-M.; Ivanova, I. Effect of Oligosaccharides on the Growth of Lactobacillus delbrueckiiSubsp.bulgaricusStrains Isolated from Dairy Products. J. Agric. Food Chem. 2009, 57, 9496-9502. [CrossRef]

19. Wu, P.Y. Mathematical Models of the Growth and Degradation of Pyrene-Degrading Bacteria; XinJiang University: Urumqi, China, 2018.

20. Altuntas, E.G.; Cosansu, S.; Ayhan, K. Some growth parameters and antimicrobial activity of a bacteriocin-producing strain Pediococcus acidilactici 13. Int. J. Food Microbiol. 2010, 141, 28-31. [CrossRef]

21. Wu, H.X.; Chen, R.; Cao, X.M.; Li, H.; Bao, Z.H.; Zhen, M.G.; Wang, J.Q.; Luo, Z.H. Optimization of fermentation medium for spore production and flask-shaking fermentation conditions of marine bacteria GM-1-1. J. South. Agric. 2018, 49, 2454-2462.

22. Kang, C.; Wen, T.-C.; Kang, J.-C.; Meng, Z.-B.; Li, G.-R.; Hyde, K.D. Optimization of Large-Scale Culture Conditions for the Production of Cordycepin with Cordyceps militarisby Liquid Static Culture. Sci. World J. 2014, 2014, 1-15. [CrossRef]

23. Ren, X.; He, L.; Cheng, J.; Chang, J. Optimization of the Solid-state Fermentation and Properties of a Polysaccharide from Paecilomyces cicadae (Miquel) Samson and Its Antioxidant Activities In Vitro. PLoS ONE 2014, 9, e87578. [CrossRef] [PubMed] 
24. Zolgharnein, J.; Shahmoradi, A.; Ghasemi, J.B. Comparative study of Box-Behnken, central composite, and Doehlert matrix for multivariate optimization of $\mathrm{Pb}$ (II) adsorption ontoRobiniatree leaves. J. Chemom. 2013, 27, 12-20. [CrossRef]

25. Rezende, C.; Almeida, M.; Brito, R.; Nonaka, C.; Leite, M. Optimisation and validation of a quantitative and confirmatory LC-MS method for multi-residue analyses of $\beta$-lactam and tetracycline antibiotics in bovine muscle. Food Addit. Contam. Part A 2012, 29, 541-549. [CrossRef]

26. Xin, D.; Xiao, L.; Cheng, L.I. Optimization of fermentation conditions for preparation of antioxidant peptides from Yak blood antioxidant peptides with Bacillus subtilis. Food Mach. 2016, 32, 165-205.

27. Khoshayand, F.; Goodarzi, S.; Shahverdi, A.R.; Khoshayand, M.R. Optimization of Culture Conditions for Fermentation of Soymilk Using Lactobacillus casei by Response Surface Methodology. Probiotics Antimicrob. Proteins 2011, 3, 159-167. [CrossRef]

28. Divya, L.M.; Prasanth, G.K.; Sadasivan, C. Isolation of a salt tolerant laccase secreting of Trichoderma sp. NFCCI-2745 and optimization of culture conditions and assessing its effectiveness in treating saline phenolic effluents. J. Environ. Sci. 2013, 25, 2410-2416. [CrossRef]

29. Huang, J.; Ou, Y.; Zhang, D.; Zhang, G.; Pan, Y. Optimization of the culture condition of Bacillus mucilaginous using Agaricus bisporus industrial wastewater by Plackett-Burman combined with Box-Behnken response surface method. AMB Express 2018, 8, 141. [CrossRef]

30. Tanyildizi, M.S.; Özer, D.; Elibol, M. Optimization of $\alpha$-amylase production by Bacillus sp. using response surface methodology. Process. Biochem. 2005, 40, 2291-2296. [CrossRef]

31. Elazazy, M.S.; El-Hamshary, M.; Sakr, M.; Al-Easa, H.S. Plackett-Burman and Box-Behnken designs as chemometric tools for micro-determination of 1-Ornithine. Spectrochim. Acta Part A Mol. Biomol. Spectrosc. 2018, 193, 397-406. [CrossRef]

32. Chaudhary, P.; Chhokar, V.; Choudhary, P.; Kumar, A.; Beniwal, V. Optimization of chromium and tannic acid bioremediation by Aspergillus niveus using Plackett-Burman design and response surface methodology. AMB Express 2017, 7, 201. [CrossRef] [PubMed]

33. Ahmad, Z.S.; Munaim, M.S.A. Response surface methodology based optimization of sorbitol production via solid state fermentation process. Eng. Agric. Environ. Food 2019, 12, 150-154. [CrossRef]

(C) 2020 by the authors. Licensee MDPI, Basel, Switzerland. This article is an open access article distributed under the terms and conditions of the Creative Commons Attribution (CC BY) license (http://creativecommons.org/licenses/by/4.0/). 